\title{
Changing Regional Urban Systems in Hiroshima Prefecture
}

\author{
Hiroshi MoRIKAwA*
}

\begin{abstract}
The author examined the changing features of regional urban systems corresponding to changing regional structure in the last few decades with Hiroshima prefecture as case study. Especial attention was paid to clarifying the changing role of small towns. It was found that the Hiroshima metropolitan area had grown remarkably in recent years, expanding regional disparities between it and other areas. Hiroshima has also strengthened functional linkages to large centers within Hiroshima prefecture, particularly to Fukuyama. Because of the rapid growth of Hiroshima in such a small prefectural area, however, horizontal linkages between small and medium-sized cities to each other have hardly been developed. Unlike small towns in Western countries which grow in "amenity-rich" rural regions, most of them have been declining or, at best, stagnating under unfavorable conditions of living. But there are a few centers with small commuting areas, such as Yoshida and Joge. The growth of these centers could contribute to the improvement of living conditions in depopulated areas.
\end{abstract}

Key words: changing regional structure, declining small towns, Hiroshima, horizontal linkages, regional urban system

\section{INTRODUCTION}

In studies of urban systems the research spotlight has focused on the top of the urban hierarchy (Hodge, 1983). The author has also mainly investigated the large centers in the national urban system forming the backbone of regional economic systems in Japan. In such studies the author regarded regional metropolises and prefectural capitals as islands floating in nonmetropolitan regions in which people can enjoy a quality of life as high as in the metropolitan areas (Morikawa, 1991). In addition, based on the analysis of interurban migrations and branch shops of commercial banks (Morikawa, $1985,1994)$, the author found that not only were hierarchical linkages developed between cities of every order but also, though less predominantly, horizontal linkages mainly between regional metropolises as well as prefectural capitals, have been developing particularly in the areas far from the Tokyo and Osaka metropolitan areas.
The author also pointed out that the prefectural areas instituted as first-order administrative areas more than 100 years ago have nowadays been developed as regional urban systems within non-metropolitan areas (Morikawa, 1990) ${ }^{11}$. They can be also classified into four types: monocentric, bicentric, polycentric and large-centric. Hiroshima prefecture, the case study of this paper, belongs to the bicentric type, because Fukuyama is slightly independent from the service area of Hiroshima. However the author has not yet examined the horizontal or non-hierarchical linkages between small and medium-sized cities with each other within or beyond a regional urban system. Have non-hierarchical linkages between them been developed similar to the regional metropolises or prefectural capitals?

The main purpose of this paper is to examine how the structure of regional urban systems has changed corresponding to the changing regional structure in the last few decades in $\mathrm{Hi}$ roshima prefecture with $2,849,847$ inhabitants in 1990 (see Figure 1). It is also important for * Department of Geography, Faculty of Letters, Univ. of Hiroshima, Higashi-Hiroshima, Hiroshima 739,
Japan 


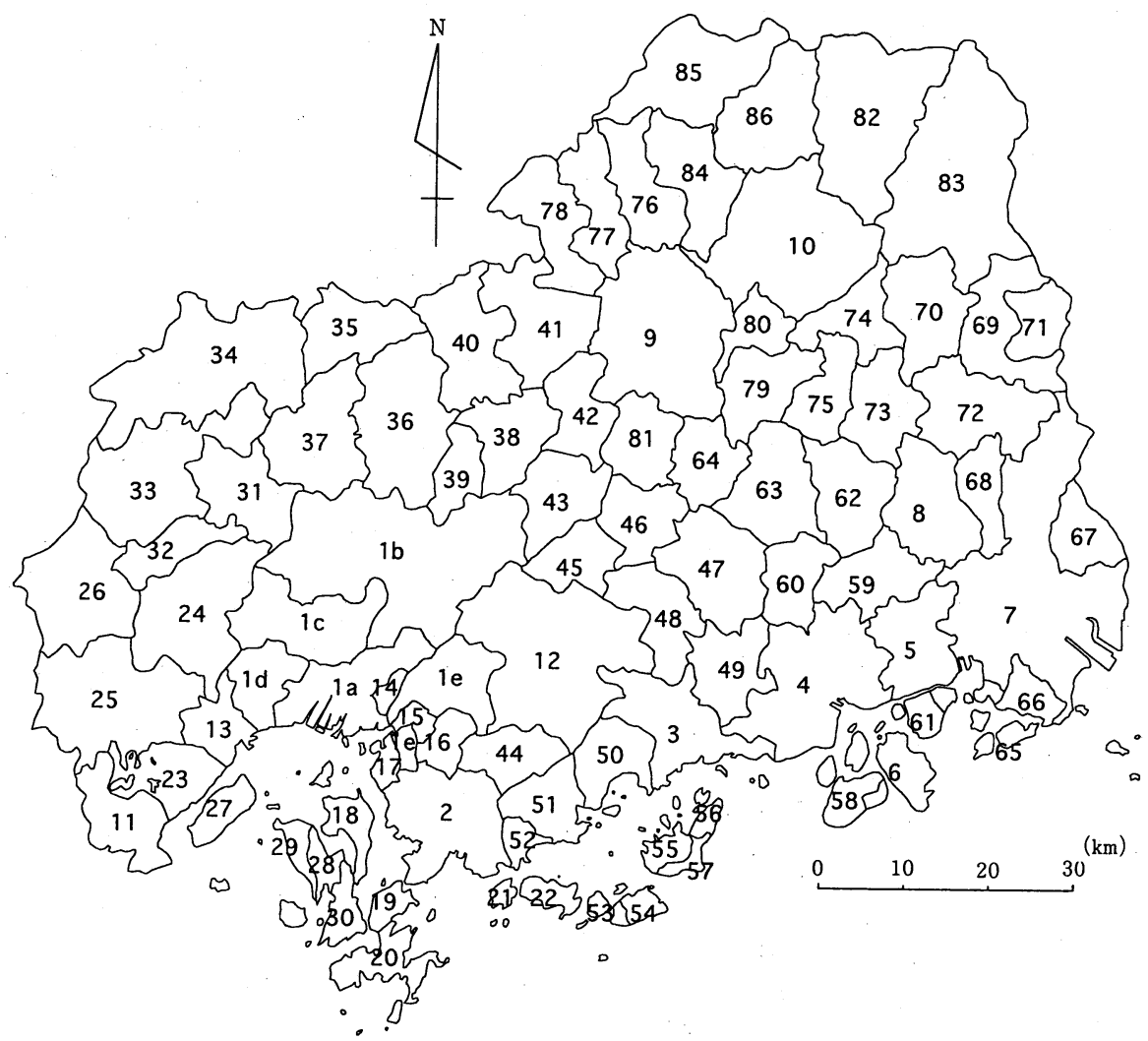

Figure 1. Municipalities in Hiroshima prefecture.

1a: Hiroshima-old wards, 1b: Asakita, 1c: Asaminami, 1d: Saeki, 1e: Aki, 2: Kure, 3: Takehara, 4: Mihara, 5: Onomichi, 6: Innoshima, 7: Fukuyama, 8: Fuchu, 9: Miyoshi, 10: Shobara, 11: Otake, 12: Higashi-Hiroshima, 13: Hatsukaichi, 14: Fuchu-cho, 15: Kaita, 16: Kumano, 17: Saka, 18: Etajima, 19: Ondo, 20: Kurahashi, 21: Shimokamagari, 22: Kamagari, 23: Ono, 24: Yuki in Saeki gun, 25: Saeki, 26: Yoshiwa, 27: Miyajima, 28: Nomi, 29: Okimi, 30: Ogaki, 31: Kake, 32: Tsutsuga, 33: Togochi, 34: Geihoku, 35: Oasa, 36: Chiyoda, 37: Toyohira, 38: Yoshida, 39: Yachiyo, 40: Midori, 41: Takamiya, 42: Koda, 43: Mukaibara, 44: Kurose, 45: Fukutomi, 46: Toyosaka, 47: Daiwa, 48: Kochi, 49: Hongo, 50: Akitsu, 51: Yasuura, 52: Kawajiri, 53: Toyohama, 54: Yutaka, 55: Osaki, 56: Higashino, 57: Kinoe, 58: Setoda, 59: Mitsuki, 60: Kui, 61: Mukaijima, 62: Kozan, 63: Sera, 64: Seranishi, 65: Utsumi, 66: Numakuma, 67: Kannabe, 68: Shin-ichi, 69: Yuki in Jinseki gun, 70: Jinseki, 71: Toyomatsu, 72: Sanwa, 73: Joge, 74: Soryo, 75: Konu, 76: Kimita, 77: Funo, 78: Sakugi, 79: Kisa, 80: Mirasaka, 81: Miwa, 82: Saijo, 83: Tojo, 84: Kuchiwa, 85: Takano, 86: Hiwa.

this study to find if and how closely small and medium-sized cities have horizontal linkages to each other. At the same time, attention should be paid to clarify the changing role of small towns and the reasons why they have experienced stagnation or decline. Since small towns are directly connected to rural areas, notably closely in depopulated areas far from large centers, it is especially important for the socioeconomic growth of rural areas to ask whether they are viable and growing or weak and declining.

Small and medium-sized cities as well as small towns in Western countries seem to be very vital, probably not independent of the pro- cess of counterurbanization which was remarkable in the 1970s. In Germany where most rural areas experienced population growth, the central function of middle-class centers (Mittelzentren) rather than that of upper-class centers (Oberzentren) has risen (Giese, 1991; Borcherdt and Bauer, 1994). Recently there appeared some workers who live in a middle-class center with the favorable living conditions and work in the surrounding rural area or in a lower order center. Moreover, Gatzweiler (1993) claimed that firms prefering to be located in mediumsized cities will increase rather than decrease in the future. In England small to medium-sized urban areas with a population between 5,000 to 
100,000 count for no less than half (47\%: 1981) of the population of England and increased their population by over 1.2 million in the decade 1971-1981 because of the attractive conditions of living (Shepherd and Congdon, 1990). In France also the growth rates of small cities with less than 50,000 inhabitants rose after the early 1960s (Pumain and Saint-Julien, 1984). The key settlement policy in the Netherlands led to the population increase of key-and independent villages based on the concentration of new housing and introduced sociocultural service facilities (de Bakker, 1986) ). $^{2}$.

Similarly, in North America some papers refer to rejuvenation or growth of small towns (Hodge and Qadeer, 1980; Burns and Trawis, 1982; Hodge, 1983; Dahms, 1988; Hart, 1988). Hodge (1983) argued that Canadian small towns and big cities have more similarities than differences in social and economic characteristics except for the level of individual incomes. Within the urban field of Canadian large cities numerous "urban" activities and agribusiness rose a few years ago, small towns became more self-sufficient and extensive commuting has been developed among settlements (Dahms, 1988). Simmons (1986) argued that the Canadian urban system led to a hierarchical convergence through more rapid growth of income in smaller towns than in larger cities. In a study of Iowa's small towns Hart (1988) pointed out that what once were rural service centers have now become processing centers.

Accordingly, the examination of the reasons why the roles of small towns differ markedly between Western countries and Japan is an important task for urban systems studies as well. The rejuvenation or growth of small towns is very important to improve living conditions of depopulated areas and to keep the whole areas of Japan in balance. Although this study mainly examines the present features, not of the 1970 s but in the period $1980-1990^{3}$, in Hiroshima prefecture, the author will investigate why such a difference has come about.

\section{THE CENTRALITY OF EACH MUNICIPALITY AND ITS CHANGES}

Although various kinds of methods for mea- suring centrality of settlements are devised, the author defines sales and service workers engaged in each municipality in 1990 as central function workers. Using this method, tourismspecialized municipalities tend to have little more than central function workers (Morikawa, 1990). But no serious problems for the analysis occur except for Miyajima, whose central function workers are somewhat numerous.

In Figure 2, which pictures a rank size curve of central function workers in 85 municipalities of the prefecture and 5 wards of Hiroshima ${ }^{4}$, we can classify them into five groups. The central function workers of Hiroshima city amount to 147,013 and 117,410 even in the old city area (four old wards) of Hiroshima, followed by Fukuyama with 42,117 persons. Accordingly, Hiroshima should form an independent group but is here classified into the same group with Fukuyama and Kure for the sake of convenience. Since as many as 42 municipalities are placed in groups of from 200 to 1,500 workers they may be divided into two groups, those over, and those under 700 workers. Although the curve rapidly drops in the municipalities of less than 100 workers in Figure 2, it is not clear whether this point delimitates between central place and non-central place municipalities. In such a classification of central place by municipalities, one cannot recognize the shape of a single group of small towns which previously were county (gun) seats or had many branch offices of the prefectural administration.

Even now, big cities, notably those with 300,000 or more population including prefectural capitals of smaller size, tend to grow more rapidly than small and medium-sized cities or small towns in Japan. In Hiroshima prefecture those municipalities with less than 300 central function workers tend to diminish between 1980 and 1990. However, there is not such a close relation between the numbers of central function workers and their growth rates (correlation coefficient: $r=0.392$ ) or population growth rates $(r=0.516)$. Consequently we cannot assume a polarization between large centers and small towns or rural municipalities because of the existence of declining large centers like Kure.

In a comparison of central places classified by 


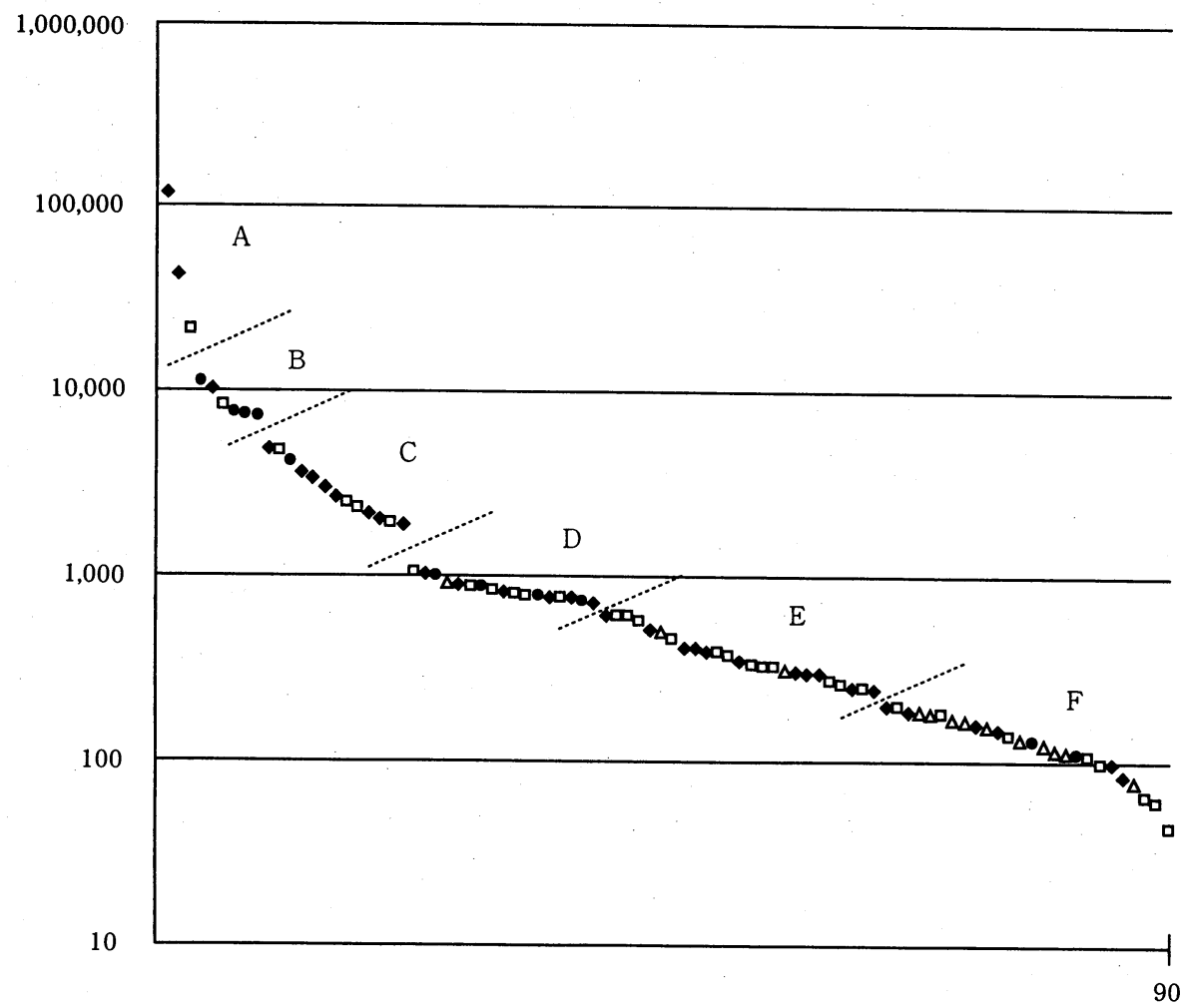

Figure 2. Rank size curve of central function workers by municipality in Hiroshima prefecture, 1990.

Sources: 1990 Population Census of Japan, and Establishment Statistics in Hiroshima prefecture (1981 and 1991). Growth rates of establishments, 1981-91

$\geqq \overline{\mathrm{x}}+\sigma \quad \Delta \overline{\mathrm{x}}+\sigma \quad \geqq \overline{\mathrm{x}} \quad \square \overline{\mathrm{x}}>\quad \geqq \overline{\mathrm{x}}-\sigma \quad \triangle<\overline{\mathrm{x}}-\sigma \quad \overline{\mathrm{x}}=-1.66 \quad \sigma=14.02$

central function workers with those classified by using the trait complex method employed in $1954 / 56$ which the author previously investigated (Morikawa, 1959) ${ }^{5}$, we can see the growth of central places in coastal areas due to urbanization and the decline due to the depopulation in inland as well as island areas (see Table 1). It is generally assumed that a number of previous central places enhanced their centrality. Most municipalities with decreasing population in inland areas have fallen in their centrality, especially in inland areas, as seen in Miyoshi, Fuchu, Shobara, Kozan-Sera, Kake, etc. Most municipalities with less than 200 central function workers are those that had no centrality in $1954 / 56$. Conversely, there are few previous central places which came to decline in centrality. Yuki in Jinseki gun (incomplete 4 class in $1954 / 56)^{6}$ is an exception in this group ${ }^{7)}$. Large scale stores (department and supermar- ket stores) have played a significant role in the modernization of the retail trade in the last three decades. In Figure 3 large scale stores with sales space of 500 or more square meters tend to be located in municipalities not only with large populations but also in those with growing populations. Several large scale stores opened in rapidly growing towns such as $\mathrm{Hi}$ gashi-Hiroshima, while in small and mediumsized cities as well as small towns in inland and island areas, large scale stores appeared through the merger of some existing small stores rather than the creation of branch shops of large firms. We can recognize a close relation between central function workers (logarithm) and the sales space of large scale stores as shown in the correlation coefficient of $r=0.685$. But there are some municipalities which lack supermarkets of more than 500 square meters despite their relatively high centrality. 


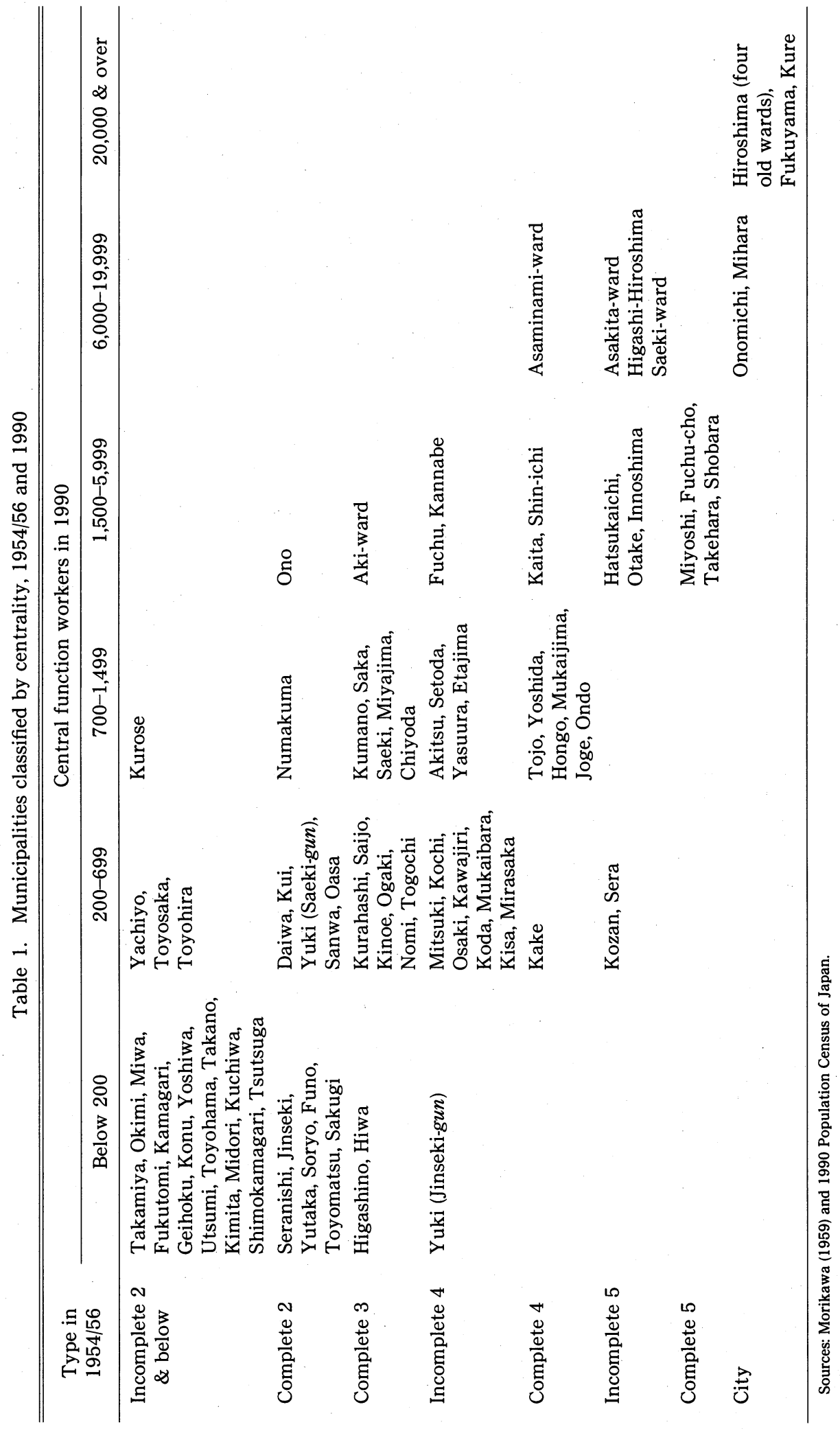




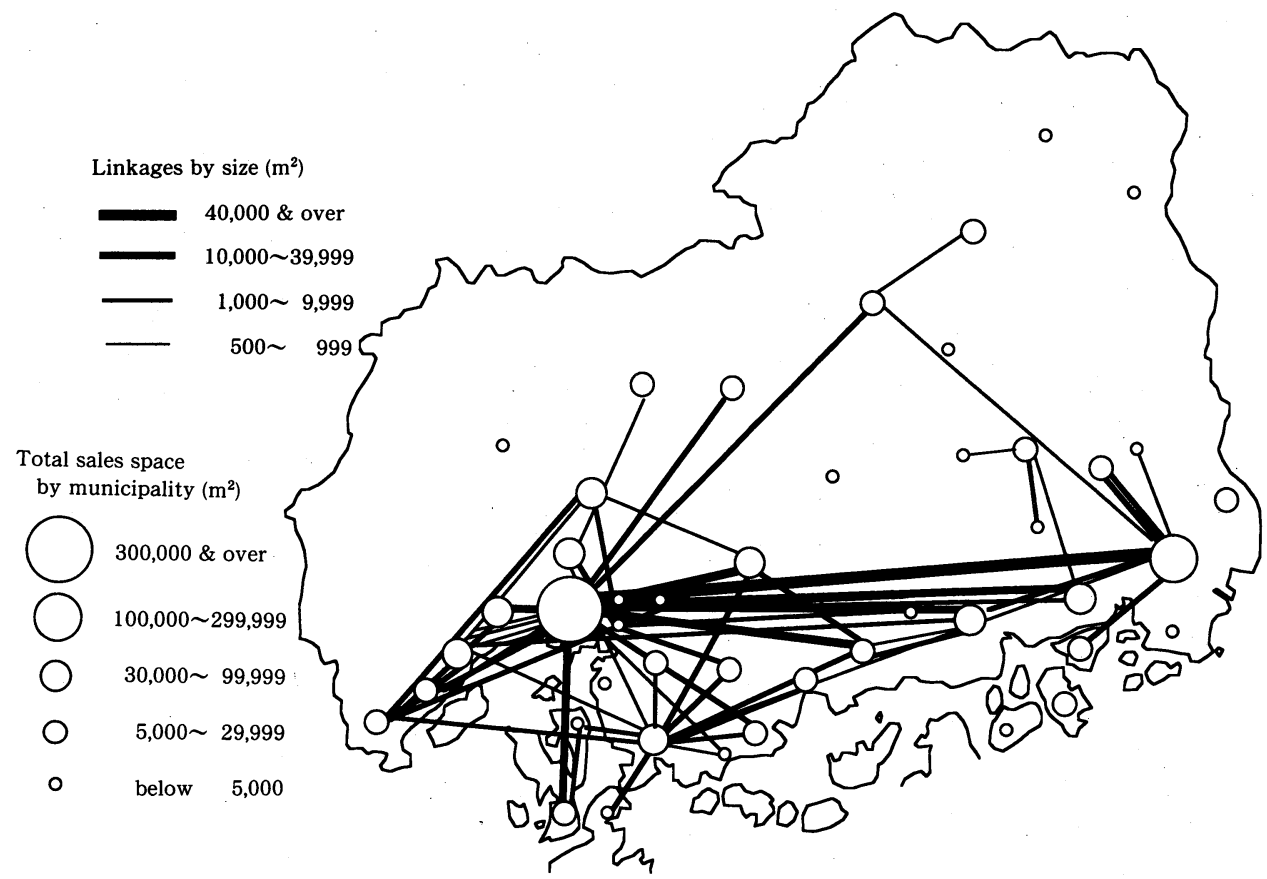

Figure 3. Large scale stores and linkages with their headquarters.

Sources: Materials from Ministry of Trade and Industry in Chugoku District and Section of Commerce and Industry, Hiroshima Prefecture.

\section{REGIONAL CHANGES AND CHANGING URBAN SYSTEMS}

Even in the rapid structural change of the Japanese economy, as represented by the development of telecommunications, the progress of the tertialization of industry and the restructuring of heavy industry in the last few decades, growth of large centers (except for a few manufacturing cities) and depopulation of inland and island areas continue in Hiroshima prefecture. Accordingly, regional disparities within the prefecture seem to have expanded. In this paper this process is confirmed by analysis of distribution and changes in population, workers, job structure and education level ${ }^{8}$.

The main occupation groups (major groups) based on the place-of-work of labor force in the 1990 Population Census of Japan consist of central function workers, management function workers $^{9)}$ and craftsmen, production process workers and laborers (CPLs). The more the central function workers (log.), the higher the rates of central function and management function workers; correlation coefficients amount to 0.719 and 0.800 , respectively. However, the central places of higher order do not have high rates of CPLs $(r=0.371)$. The majority of CPLs are engaged in the municipalities around large centers rather than in the centers themselves, while the depopulated areas have low rates of CPLs due to unfavorable conditions of transportation.

The correlation coefficients between central function workers (log.) and population growth rates, as well as growth rates of total workers in each municipality in the period 1980-1990 indicate 0.516 and 0.538 . The reason for relatively lower values rests on the fact that the number of workers does not increase correspondingly with the population increase because of a number of commuters who work in Hiroshima or Fukuyama.

Among the average growth rates of abovementioned workers of three jobs in the decade 1980-1990 in the prefecture, management function workers grew at the highest rate of $22.4 \%$, followed by central function workers (9.1\%) and CPLs (1.8\%). Even the municipalities with 
decreasing central function workers and CPLs seldom decreased their management workers. In the process of tertiarization, it seems reasonable that management function workers are growing in most municipalities. Nevertheless, only low correlation coefficients of less than $\mathrm{r}=0.4$ are indicated between central function workers of municipalities (log.) and the growth rates of each of these three job workers. This is because there are a few slowly growing cities in large centers as mentioned above.

Viewed as percentages of young workers (15 to 29 years old in 1990) for each municipality, there appears to be a relatively close relation between them and central function workers. A municipality can have sustainable jobs in the future when it has relatively high percentages of young workers, the converse leading to future decrease in jobs. Although jobs can be filled with the employment of middle-aged and aged workers, this seems to be an unsound policy for the development of jobs in a municipality.

Figure 4 deals with the percentages of young workers for each municipality. It indicates a spatial pattern corresponding to the advance of urbanization and depopulation. The municipalities with more than $20 \%{ }^{10)}$ of young workers are located only in the surrounding areas of Hiroshima-Kure and Fukuyama while those with young workers of 10 to $20 \%$ are distributed on the periphery of such regions. The correlation between central function workers (log.) and percentages of young workers is so close $(r=0.842)$ that the higher development for a municipality with higher percentages of young workers can be expected. It is noticeable that young workers can be sustained even in cities with low growth rates of population and central function workers. The recent population decrease due to business depression does not significantly affect the maintenance of succeeding workers.

Each of three main jobs of young workers is also clearly correlated with central function workers (log.) ( $r=0.873,0.705$ and 0.739). Similar to Figure 4, the percentages of young workers for each job are also high in the coastal area

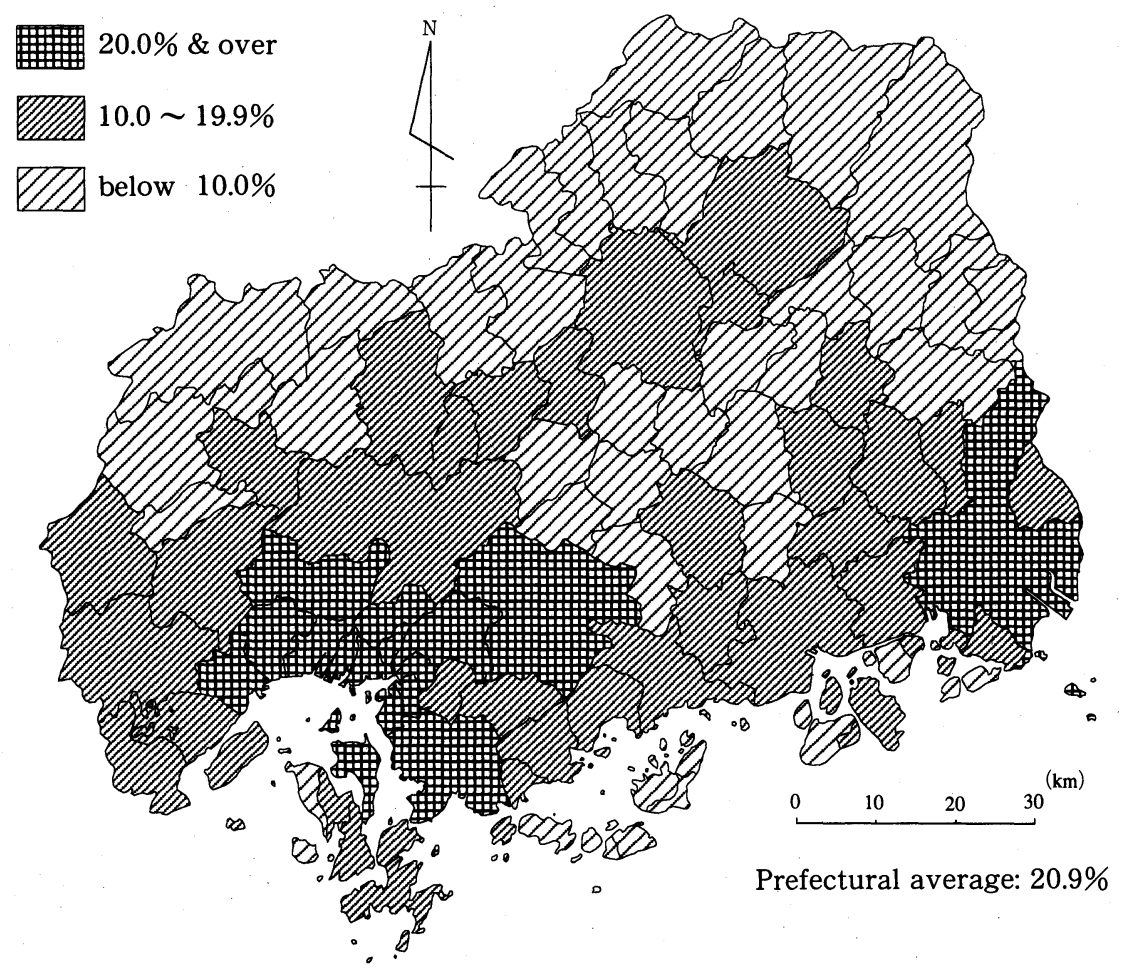

Figure 4. Percentages in young workers (15-29 years old), 1990. Source: 1990 Population Census of Japan. 
and in areas surrounding small inland cities such as Miyoshi. In rural areas young workers will decrease further in the future. Especially in CPLs, the percentages of distribution of young workers is markedly different from the present percentages of CPLs; in the future it will more closely correspond to the population size of a municipality.

Percentages of highly qualified workers are also an important key to regional disparities. Rural areas are unfavorable as working and living places for university and junior college graduates $^{11)}$. Most young people leaving for universities will not return home. High-tech firms prefer not to establish a plant in rural areas. As Figure 5 shows, the percentages of university and junior college graduates are high in coastal areas; Hatsukaichi (16.7\%) and Hiroshima (15.7\%) show the highest values (prefectural average: $6.6 \%$ ). The percentages of highly qualified workers are closely correlated with central function workers (log.) $(r=0.825)$. Because of higher growth rates of university and junior college graduates in large centers, regional dis- parities will enlarge more and more in the future. Of course, such a phenomenon is not confined to Japan; Pompili (1992) pointed out the regional disparities of human capitals corresponding to the urban hierarchy in Italy, and Meusburger (1993) recognizes the expanding tendency of the hierarchical division of labor due to the qualification of jobs in European countries.

In short, regional disparities between urban and rural areas will tend to be aggravated in the future. Since Hiroshima and its surrounding areas raise their centrality through rapid urbanization, central function workers as well as other main job workers will increase, as will jobs for highly qualified workers. Sustainable rates of young workers also become high there. The Hiroshima metropolitan area is the most favorable one in Hiroshima prefecture not only at present, but also in the future, followed by the Fukuyama area which continues its autonomous growth but is not so vital in comparison to the Hiroshima area. In most areas other than Hiroshima and Fukuyama, central function

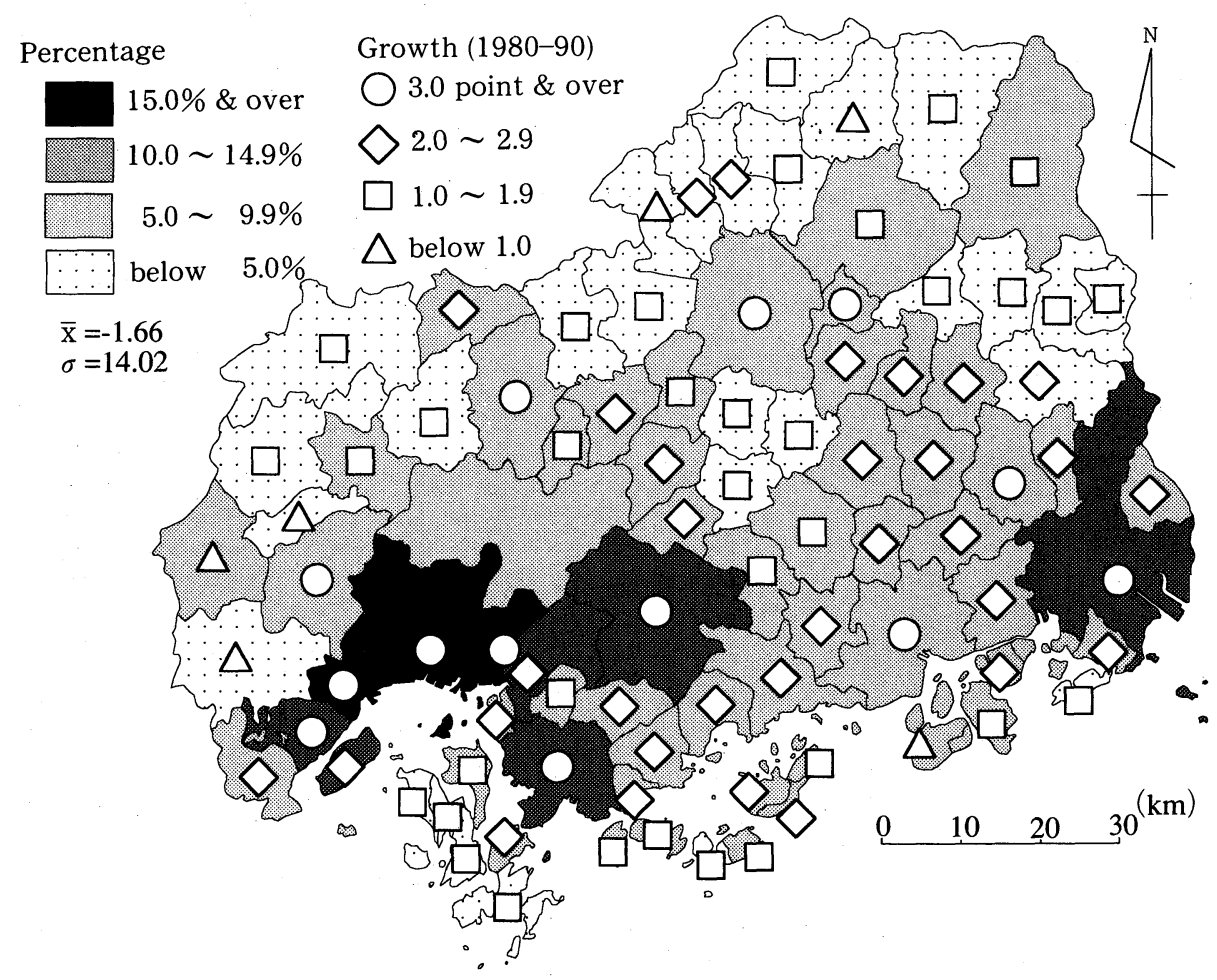

Figure 5. Percentages in and growth of university and junior college graduates, 1990. Sources: 1980 and 1990 Population Censuses of Japan. 
workers are stagnant or decreasing. Jobs for young people as well as highly qualified workers are so insufficient that regional development cannot be expected in the future. In addition to this general tendency there are a few cities, such as Kure, with unfavorable conditions based on structurally weak industries.

\section{FUNCTIONAL LINKAGES BETWEEN MUNICIPALITIES}

\section{Migration flows}

As the most important gateway within the prefecture, Hiroshima has close linkages of migration flows (in- and outflows) with the Tokyo and Osaka large metropolitan areas. In 1989/90 Hiroshima had migration flows to Tokyo prefecture (7,054 persons) and Osaka prefecture (6,594 persons) of 13,638 persons or $1.12 \%$ in total. Since both metropolitan areas are not ac- tually delimited in their own prefectural areas, we should estimate that Hiroshima is connected by strong ties to these large metropolitan areas. The rates of migration flow to other prefectures are generally higher in coastal areas than in inland areas. The western part of the coastal area is predominantly connected to the Tokyo metropolitan area, while cities and island municipalities in the southeastern part of the prefecture are more closely connected to Osaka than to Tokyo.

Figure 6 shows all migration flows of more than $0.5 \%$ of the total population to a specific center ${ }^{12}$, in order to examine the complex structure of linkages between municipalities in the prefectural area. Within the Hiroshima metropolitan area, the four old wards shape the largest nodal center for migration flows of population, while each of the four new wards, Asakita, Asaminami, Aki and Saeki, also form small nodal centers. Furthermore, satellite towns

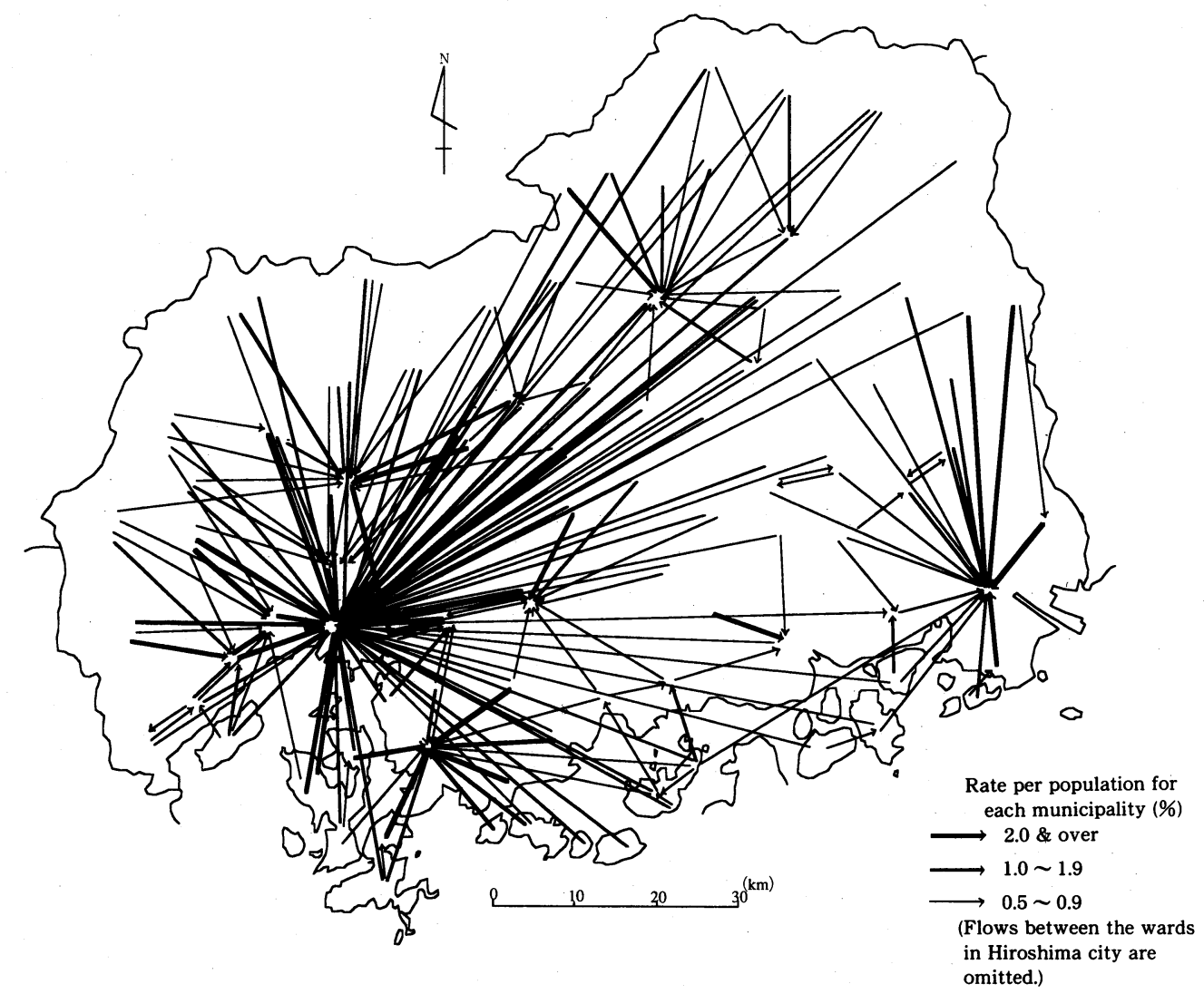

Figure 6. Migration flows, 1989/90.

Source: Report of Migration Statistics in Hiroshima Prefecture (1. Oct. 1989-30. Sept. 1990). 
such as Hatsukaichi and Higashi-Hiroshima are added to these nodal centers. HigashiHiroshima has expanded the extent of migration flows through its rapid urbanization. Therefore, the Hiroshima metropolitan area forms a hierarchical structure of migration flows with centers of intermediate order.

In contrast, Fukuyama is a center of migration flows in the southeastern part of the prefecture ${ }^{13)}$, but the mutual migration flows among Fukuyama, Onomichi and Mihara are not so vital (only $0.38 \%$ between Onomichi and Mihara). Their values are remarkably less than those estimated by employing the simple gravity model.

Figure 7 demonstrates the vertical structure of functional linkages between municipalities, by showing the size of central function workers of each municipality on the vertical axis and the physical distance from Hiroshima to each municipality on the horizontal axis ${ }^{14)}$, and by connecting more than $0.5 \%$ of migration flows between municipalities with a straight line. Furthermore, the growth rates of central function workers for each municipality in the decade 1980-1990 are added in order to show the growth of municipalities.

It goes without saying that Hiroshima stands at the top of the regional urban system of Hiroshima prefecture and has close linkages with almost all municipalities. Although the rate of migration flows between Hiroshima (four old wards) and Fukuyama is as low as $0.87 \%$, the migration flows amount to 1,984 persons. After the Reports of Migration Statistics in Hiroshima Prefecture in the period 1967-1993 the migration flows between both cities increased with higher growth rates, in comparison to the

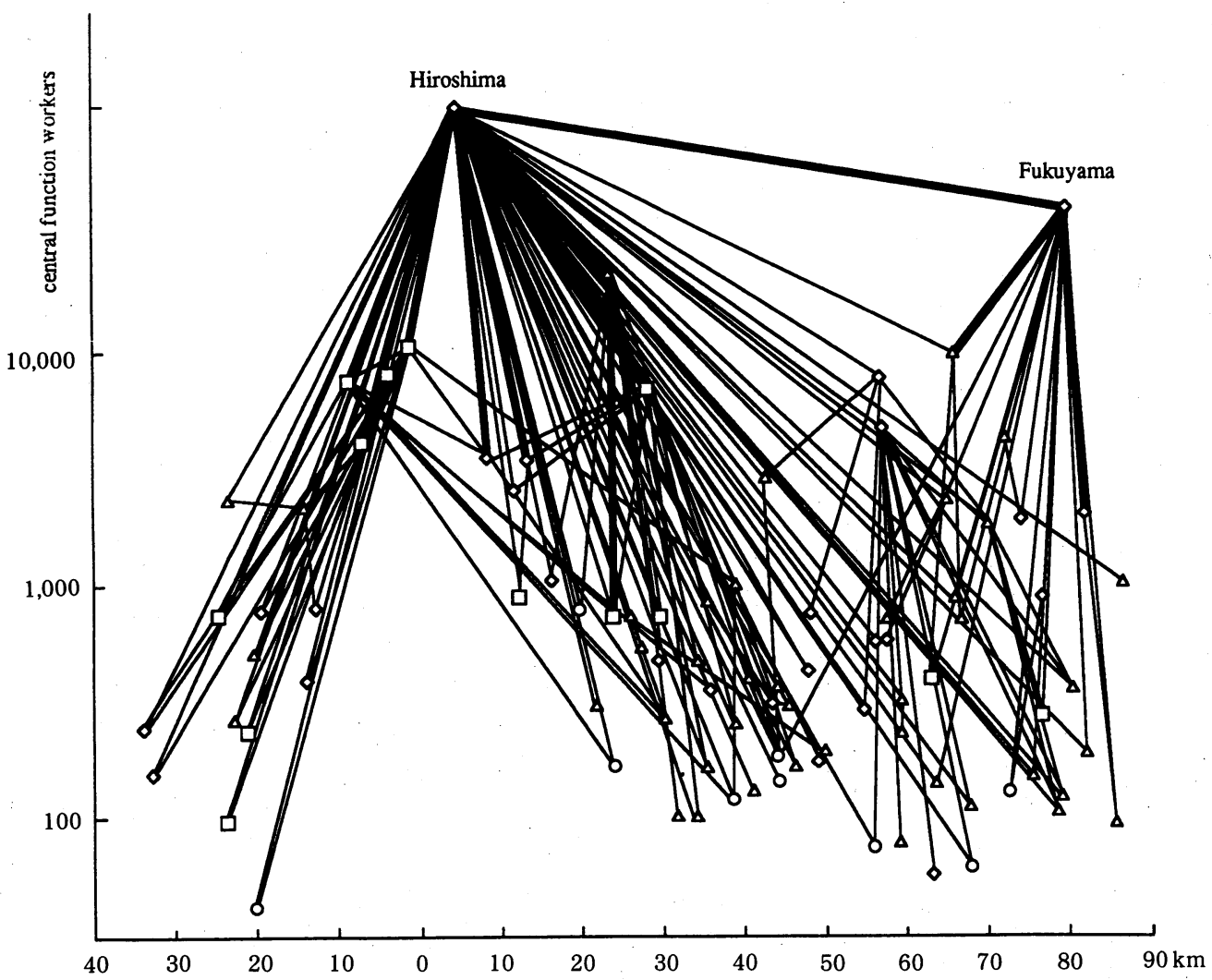

Figure 7. The structure of regional urban systems in Hiroshima prefecture.

Sources: 1980 and 1990 Population Censuses of Japan. Growth rates of central function, 1980-90 (\%)

$\square 16.7$ \& over $\diamond-1.7 \sim 16.6 \quad \Delta-1.8 \sim-20.0 \quad \bigcirc$ below -20.0

Migration flows with rates of over $0.5 \%$ of population (persons)

2,000 \& over - 1,000 1,999 - below 1,000 
migration flows between Hiroshima or Fukuyama and Tokyo and Osaka prefectures, as shown in Table 2. Such a tendency of strengthening linkages should be noted as the changing feature of the regional urban system. It seems that only large centers like Fukuyama have reinforced functional linkages with Hiroshima in the processes of its growth. Mihara and Mi-

Table 2. Migration flows in Hiroshima prefecture

\begin{tabular}{|c|c|c|c|c|c|c|}
\hline \multirow{2}{*}{ Year } & \multicolumn{3}{|c|}{ Total migration flows } & \multicolumn{3}{|c|}{ Within the prefecture } \\
\hline & number & \multicolumn{2}{|c|}{$1967=100(\mathrm{~A})$} & number & \multicolumn{2}{|c|}{$1967=100(B)$} \\
\hline 1967 & 234,159 & \multicolumn{2}{|c|}{100.0} & 86,769 & \multicolumn{2}{|c|}{100.0} \\
\hline 1970 & 280,613 & \multicolumn{2}{|c|}{119.8} & 101,475 & \multicolumn{2}{|c|}{116.9} \\
\hline 1975 & 236,352 & \multicolumn{2}{|c|}{101.0} & 78,280 & \multicolumn{2}{|c|}{90.2} \\
\hline 1980 & 249,976 & \multicolumn{2}{|c|}{106.8} & 98,931 & \multicolumn{2}{|c|}{114.0} \\
\hline 1985 & 244,181 & \multicolumn{2}{|c|}{104.3} & 93,043 & \multicolumn{2}{|c|}{107.2} \\
\hline 1990 & 231,220 & \multicolumn{2}{|c|}{98.7} & 90,782 & \multicolumn{2}{|c|}{104.6} \\
\hline 1993 & 207,492 & \multicolumn{2}{|c|}{88.6} & 79,218 & & \\
\hline & $\mathrm{Hir}$ & shima-Fukuya & & Hiroshima & (4 old wards)-F & yama \\
\hline Year & number & $1967=100(\mathrm{C})$ & $\mathrm{C} / \mathrm{A}$ & number & $1967=100(\mathrm{D})$ & $\mathrm{D} / \mathrm{A}$ \\
\hline 1967 & 2,085 & 100.0 & 100.0 & 1,525 & 100.0 & 100.0 \\
\hline 1970 & 3,264 & 156.5 & 130.6 & 2,382 & 156.2 & 130.3 \\
\hline 1975 & 3,051 & 146.3 & 144.9 & n.a. & n.a. & n.a. \\
\hline 1980 & 4,952 & 237.5 & 222.5 & 1,855 & 121.6 & 113.9 \\
\hline 1985 & 5,304 & 254.4 & 243.9 & 2,096 & 137.4 & 131.8 \\
\hline 1990 & 5,178 & 248.3 & 251.5 & 1,984 & 130.1 & 131.8 \\
\hline 1993 & 4,189 & 200.9 & 226.7 & 1,564 & 102.6 & 115.7 \\
\hline & Hirc & shima-Tokyo $\mathrm{p}$ & & Hiroshima & (4 old wards)-T & pref. \\
\hline Year & number & $1967=100(\mathrm{E})$ & $\mathrm{E} / \mathrm{A}$ & number & $1967=100(\mathrm{~F})$ & $\mathrm{F} / \mathrm{A}$ \\
\hline 1967 & 6,480 & 100.0 & 100.0 & 5,282 & 100.0 & 100.0 \\
\hline 1970 & 7,775 & 120.0 & 100.1 & 5,993 & 113.5 & 94.7 \\
\hline 1975 & 7,157 & 110.4 & 109.3 & n.a. & n.a. & n.a. \\
\hline 1980 & 6,923 & 106.8 & 100.1 & 4,860 & 92.0 & 86.2 \\
\hline 1985 & 8,108 & 125.1 & 120.0 & 5,274 & 99.8 & 95.8 \\
\hline 1990 & 7,054 & 108.9 & 110.2 & 4,489 & 85.0 & 86.1 \\
\hline 1993 & 6,280 & 96.9 & 109.4 & 3,630 & 68.7 & 77.6 \\
\hline & Hir & shima-Osaka p & & Hiroshima & (4 old wards) $-C$ & pref. \\
\hline Year & number & $1967=100(\mathrm{G})$ & G/A & number & $1967=100(\mathrm{H})$ & $\mathrm{H} / \mathrm{A}$ \\
\hline 1967 & 6,170 & 100.0 & 100.0 & 4,809 & 100.0 & 100.0 \\
\hline 1970 & 7,468 & 121.0 & 101.0 & 5,361 & 111.5 & 93.0 \\
\hline 1975 & 7,050 & 114.3 & 113.1 & n.a. & n.a. & n.a. \\
\hline 1980 & 6,080 & 98.5 & 92.3 & 3,749 & 78.0 & 73.0 \\
\hline 1985 & 7,113 & 115.3 & 110.6 & 4,069 & 84.6 & 81.1 \\
\hline 1990 & 6,594 & 106.9 & 108.2 & 3,474 & 72.2 & 73.2 \\
\hline 1993 & 5,710 & 92.5 & 104.4 & 3,000 & 62.4 & 70.4 \\
\hline & Fuk & uyama-Tokyo & & Fuk & uyama-Osaka $\mathrm{p}$ & \\
\hline Year & number & $1967=100(\mathrm{I})$ & I/A & number & $1967=100(\mathrm{~J})$ & $\mathrm{J} / \mathrm{A}$ \\
\hline 1967 & 1,249 & 100.0 & 100.0 & 2,006 & 100.0 & 100.0 \\
\hline 1970 & 1,895 & 151.7 & 126.6 & 2,959 & 147.5 & 123.1 \\
\hline 1975 & 1,558 & 124.7 & 123.5 & 2,356 & 117.4 & 116.3 \\
\hline 1980 & 1,472 & 117.9 & 110.4 & 2,067 & 103.0 & 96.5 \\
\hline 1985 & 1,489 & 119.2 & 114.3 & 1,571 & 78.3 & 75.1 \\
\hline 1990 & 1,282 & 102.6 & 103.9 & 1,804 & 89.9 & 91.1 \\
\hline 1993 & 1,073 & 85.9 & 96.9 & 1,431 & 71.3 & 80.5 \\
\hline
\end{tabular}


yoshi do not correspond to such an example ${ }^{15}$. Although the author has not yet undertaken case studies in other prefectures, it can be assumed that the functional linkages between large centers within a regional urban system may be reinforced in the process of its development.

In the Hiroshima metropolitan area Kure, Asaminami ward, Asakita ward, Hatsukaichi and Higashi-Hiroshima form the migration centers of intermediate order. Mihara, Miyoshi and Shobara are also small centers at a distance from Hiroshima. On the other hand, Fukuyama forms its own migration area in the southeastern part of the prefecture.

Viewing Figure 7, even within the complex flows of more than $0.5 \%$ of total population, nodal (hierarchical) flows are usually so dominant that horizontal linkages between municipalities of the same order seem not to be intensively developed. This is because Hiroshima is a predominant center in the prefectural area $^{16)}$, as the author already demonstrated through analysis of the distribution of branch banks (Morikawa, 1994).

The growth rates of central function workers for most municipalities with less than 200 workers remained below the prefectural average $(-1.7 \%)$ in the decade $1980-1990$. Remote municipalities in inland and island areas are generally declining, while in the surrounding area of Hiroshima there are some municipalities with increasing central function workers. Viewed from the growth rates of migration flows, Yuki in Saeki gun (176.9\%), Kurose (104.8\%), Hatsukaichi (58.1\%) and HigashiHiroshima (42.3\%) evidently increased their migration flows with Hiroshima.

It means that in the process of rapid urbanization the hierarchical system of the Hiroshima metropolitan area alone has risen more highly than other parts of the prefectural area. The fact that regional metropolises and prefectural capitals seem to be islands floating in nonmetropolitan regions becomes more evident than before. Thus, we can conclude that the regional disparities have expanded between the Hiroshima metropolitan area-partially including the Fukuyama area-and other areas.

\section{The location of private establishments and their headquarters}

A study on the location of branch offices and headquarters of firms is also significant for the observation of functional linkages between cities or towns. What kinds of branch offices are there and which centers of the hierarchical order are they located in? How are they now structurally transforming?

In Table 3 single establishments make up a large share of the private companies in 1991. The percentage of headquarters amounts to only $5.0 \%$ in prefectural average, considerably lower than $18.6 \%$ for branch offices. The municipalities with higher percentages of branch offices than the prefectural average (18.6\%) are located mostly in the Hiroshima metropolitan area; Mihara (19.1\%), Miyoshi (21.4\%), Chiyoda (18.6\%), Toyohira (18.6\%), Midori (19.9\%) and Hongo (19.5\%) show higher percentages as well as Hiroshima (23.0\%; four old wards $24.3 \%$ ). But the reasons why rural municipalities such as Toyohira and Midori have high percentages seem to be different from the large centers ${ }^{17}$. Fukuyama amounts to $17.6 \%$, a little below the prefectural average for branch offices.

Table 3 also indicates that the average percentages for branch offices whose headquarters are located within the prefecture $(5.7 \%)$ are a little higher than those located in the Tokyo and Osaka metropolitan areas (4.4\%). Most municipalities in the former are located in the surrounding area of Hiroshima. In contrast, large centers such as Hiroshima, Fukuyama and Kure have higher percentages of headquarters which are located in the Tokyo and Osaka metropolitan areas. They are markedly concentrated in Hiroshima (4,494 companies; four old wards 4,065$)$ compared to Fukuyama (818) and Kure (296). When converted to percentages of the total number of establishments for each municipality, Hiroshima has the highest percentage with $7.7 \%$ (four old wards $9.5 \%$ ), followed by Fukuyama (3.8\%), Mihara (3.5\%) and Hongo (3.4\%). The relatively high percentage of Hongo seems to be due to the construction of the new Hiroshima airport.

The average growth rate of private establishments in the period 1981-1991 amounts to 
Table 3. Establishments, headquarters and branch offices in municipalities classified by central function workers

\begin{tabular}{|c|c|c|c|c|c|c|c|c|}
\hline \multirow{2}{*}{ Group } & \multicolumn{3}{|c|}{ Number } & \multicolumn{5}{|c|}{ Percentage } \\
\hline & Municipalities & \multicolumn{2}{|c|}{ Total establishments } & Headquarters $\mathrm{B}$ & Branch offices & $\mathrm{AA}$ & BB & $\mathrm{CC}$ \\
\hline $\mathrm{A}$ & 3 & \multicolumn{2}{|c|}{25,266} & 5.4 & 19.5 & 4.2 & 5.3 & 0.9 \\
\hline B & 6 & \multicolumn{2}{|c|}{4,709} & 4.7 & 19.9 & 8.8 & 3.0 & 0.6 \\
\hline $\mathrm{C}$ & 13 & \multicolumn{2}{|c|}{1,818} & 5.0 & 16.0 & 6.6 & 2.1 & 0.7 \\
\hline $\mathrm{D}$ & 17 & \multicolumn{2}{|c|}{618} & 4.1 & 13.6 & 6.8 & 1.4 & 0.3 \\
\hline $\mathrm{E}$ & 25 & \multicolumn{2}{|c|}{359} & 3.4 & 10.7 & 5.4 & 0.6 & 0.2 \\
\hline $\mathrm{F}$ & 26 & \multicolumn{2}{|c|}{159} & 2.6 & 9.6 & 4.3 & 0.3 & 0.3 \\
\hline Total & 90 & \multicolumn{2}{|c|}{32,929} & 5.0 & 18.6 & 5.7 & 4.4 & 0.7 \\
\hline \multirow{2}{*}{ Group } & \multicolumn{8}{|c|}{ Growth rate $(1981-91, \%)$} \\
\hline & Total establis & hments & Headquarters & Branch offices & AA & $\mathrm{BB}^{*}$ & & $\mathrm{CC}^{*}$ \\
\hline $\mathrm{A}$ & 1.9 & & 6.6 & 27.8 & 125.3 & 34.3 & & 64.7 \\
\hline B & 13.9 & & 30.1 & 46.2 & 266.9 & 67.0 & & 72.7 \\
\hline C & 3.6 & & 23.3 & 31.0 & 61.4 & 29.8 & & 61.3 \\
\hline D & 3.5 & & 67.3 & 50.5 & 76.1 & 75.4 & & 31.1 \\
\hline E & -4.5 & & 60.1 & 16.8 & 37.1 & 32.3 & & 10.7 \\
\hline $\mathrm{F}$ & -9.5 & & 44.0 & 8.8 & 23.2 & -5.8 & & 0.0 \\
\hline Total & 4.5 & & 11.7 & 31.2 & 92.4 & 36.6 & & 49.9 \\
\hline
\end{tabular}

Groups A to F correspond to the classification in Figure 2. AA: Branch offices headquartered within the prefecture. BB: Headquartered in Tokyo and Osaka prefectures. CC: Headquartered in other prefectures in the Chugoku destrict. *The values not to be calculated are dealt with 0 value.

Source: Report of Research Results on Establishments in Hiroshima Prefecture, 1990.

4.5\% in Hiroshima prefecture. The surrounding municipalities of Hiroshima such as HigashiHiroshima (23.5\%), Hatsukaichi (23.6\%) and Kurose $(32.8 \%)$ show the highest growth rates of such establishments. The four old wards of Hiroshima, Fukuyama and Kure increased with the rates of $4.0 \%, 7.0 \%$ and $-5.1 \%$, respectively. Generally speaking, relatively larger centers with central function workers of more than 700 persons tend to increase more rapidly than the prefectural average, while the growth rates of private establishments in most of the small towns and rural municipalities remain below average.

The growth rate of branch offices in the last decade amounts to $31.2 \%$ of the prefectural average. The growth rates of branch offices whose headquarters are located in large metropolitan areas and within the prefectural area amount to $36.6 \%$ and $92.6 \%$, respectively. It is noticeable that the growth rates of branch offices for the latter are higher than those for the former; particularly, they are very high in the Hiroshima metropolitan area, especially the four old wards (312.1\%), Asakita ward (887.5\%), Asaminami ward (535.9\%), Aki ward
(266.0\%) and Kurose (218.8\%). Other cities such as Fukuyama (24.6\%), Kure (39.1\%), Onomichi (29.1\%), Mihara (12.5\%) and Miyoshi (22.9\%) have only low growth rates. In rural areas, only a few municipalities have high growth rates. However, since the rural areas originally had few private establishments to begin with, they are very few in number despite having high growth rates. The expanding regional disparities between the Hiroshima metropolitan area and other cities are also confirmed from such rapid growth of branch offices in the Hiroshima metropolitan area.

In short, large centers have higher values for each of the rates of headquarters, total branch offices and branch offices whose headquarters are located in large metropolitan areas. Similarly, such growth rates of total establishments are high in large centers except for Kure. But the rates of branch offices for the prefectural firms alone do not show such a tendency; the rates are higher in medium-sized cities (cities of $B$ and $C$ classes in Figure 2) than in large centers (A class cities), as was already pointed out by Hino (1986). The growth rates of such branch offices are also higher in the majority of 
small towns than in large centers.

Thus, we can recognize a kind of hierarchical division of functions between small towns and large centers; large centers such as Hiroshima have branch offices of metropolitan firms on the one hand and a number of headquarters for the prefectural firms on the other hand, while small and medium-sized cities and some small towns have many branch offices of the latter. Large centers seem to play the role of 'connector' between branch offices of metropolitan firms and headquarters of prefectural firms which are closely connected in function and capital with the former. The fact that firms play roles as connectors of local headquarters and national branch offices seems to be very important in the Japanese urban system.

\section{Functional linkages between headquar- ters and branch stores of large scale stores}

Unfortunately we have not so much materials for the functional linkages between cities or towns. By examining the linkages between headquarters and branch stores for large scale stores in Figure 3 once again ${ }^{18)}$, we can find that the majority of headquarters are located in Hiroshima and its surrounding area. They mainly locate their branch stores in the municipalities of the coastal area. Notably, large scale stores located in Hiroshima have many branch stores in Fukuyama ${ }^{19}$. This fact demonstrates that functional linkages between both cities have been reinforced in recent years as mentioned above. It does not mean, however, that horizontal linkages have been developed as shown in Pred's model (Pred, 1971), because there exists a clear hierarchical difference between both cities. Large scale stores tend to have their branch stores in smaller cities or towns than in cities that contain their main stores.

\section{GROWTH AND DECLINE OF SMALL TOWNS}

As mentioned above, the Hiroshima metropolitan area is growing more rapidly compared to the surrounding area of Fukuyama. Accompanying the growth of Hiroshima as regional metropolis, regional centers such as Fukuyama have strengthened their linkages with Hiroshima. Except for the Hiroshima and Fukuyama areas, however, not only rural municipalities and small towns but also most of the small and medium-sized cities are declining or, at best, stagnant within the prefecutural area.

Particularly, retail and service activities of small towns which were formerly county seats and supplied various kinds of goods and services and had their own, not so large, service areas in inland area, have been strikingly damaged by the widespread automobile ownership and additionally by remarkable depopulation in their surrounding rural areas. But there are some centers with small commuting areas. As shown in Figure 8 in which all linkages of $5 \%$ or more commuting rates from each munucipality to a specific center are connected with arrows, Yoshida, Joge, Kake and Chiyoda are typical towns with commuting areas. Kozan and Sera exchange commuters with each other in a small basin. Chiyoda was not a county seat of Yamagata gun (county) but a small town with central functions. It is an exceptional case which has recently grown through the construction of industrial estates after the opening of the Chugoku superhighway.

Although the establishment and expansion of branch offices of large firms managing a part of the prefectural area is important for urban growth, branch offices or stores of household electrical appliances, automobile, medicine makers etc. are not established in these towns. For example, according to the investigation of Tsuneda (1993) the branch offices of main medicine makers are generally set in Hiroshima and Fukuyama when the prefectural area is divided into two managing areas, and then in Kure, Higashi-Hiroshima, Mihara $=$ Onomichi and Miyoshi apart from both cities when the prefectural area is divided into six. Accordingly, small towns could not strengthen their functional linkages with Hiroshima or Fukuyama as to the territorial management of large firms, even if branch offices of the prefectural firms can be located there.

In addition, the lack of administrative organizations between prefecture and municipalities is unprofitable for the growth of small towns ${ }^{20}$. After the abolishment of the gun system the gun 
Municipalities with less than $20 \%$ of workers working in other municipalities

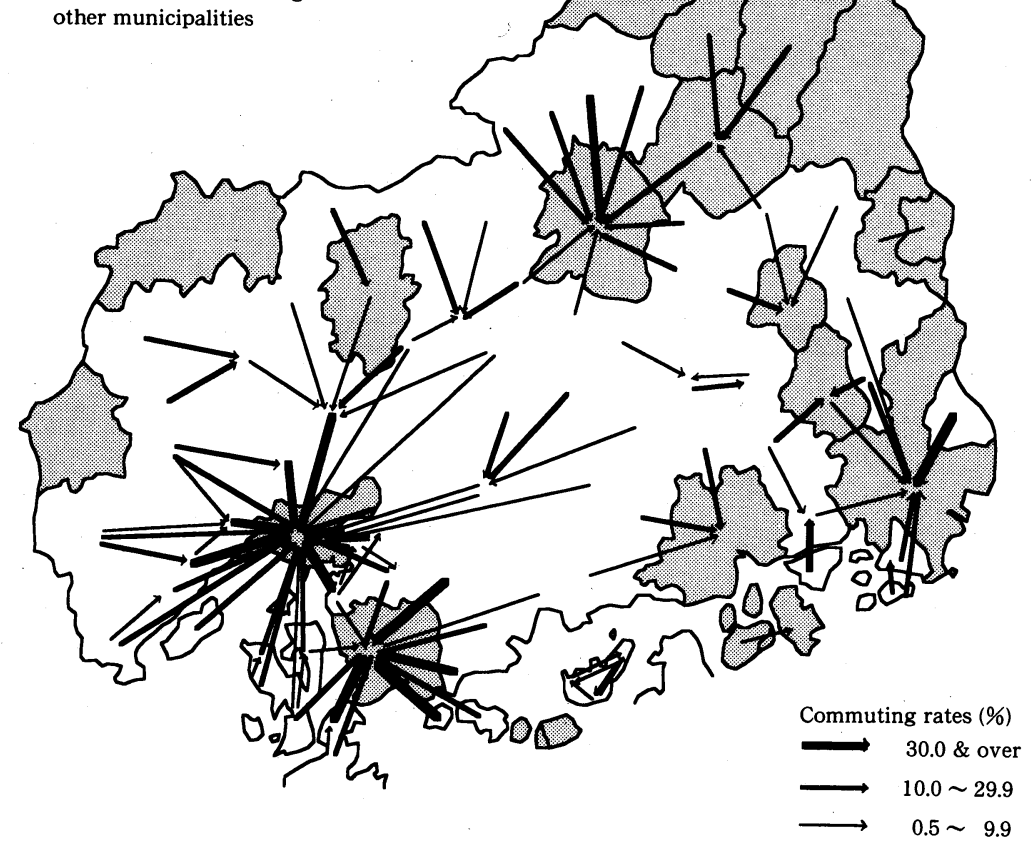

Figure 8. Rates and flows of commuting, 1990. Source: 1990 Population Census of Japan.

seat towns have largely lost their administrative functions, although branch offices of the prefectural government are located there. Moreover, the branch offices of the prefectural government tend to be integrated in large centers in the process of administrative restructuring ${ }^{21}$. Even when such integration can be avoided, the number of staff members tend to decrease. For example, Kake, the former county seat of Yamagata gun, has lost many staff members by the abolishment or reduction of its administrative offices.

Accordingly, it seems that small towns are losing their role as the lowest centers in the national urban system. The information gap between them and large centers has become serious and would be very unprofitable for their urban growth as service centers ${ }^{22}$.

Certainly, manufacturing plants have been established in rural areas as well as small towns. As described in the case of Chiyoda, industrial estates were constructed in the surrounding areas of interchanges of the Chugoku superhighway. But except for these areas, most plants located in inland areas are limited to plants of labor intensive type such as sewing and other subcontract factories. Building lots for factories are also often very scarce and limited to the bottom of narrow valleys. The shift from service centers to manufacturing towns did not evidently emerge, as Hart (1988) described. Thus, it can be safely said that most small towns could gain no profit from the processes of recent economic development.

Next, the author will refer to Joge and Yoshida in detail as two examples. Joge and Yoshida have central function workers of 771 and 1,020 respectively in 1990 and belong to the $D$ class of small towns in Table 3.

Joge is located about $47 \mathrm{~km}$ northwest of Fukuyama and about $94 \mathrm{~km}$ northeast of Hiroshima by road. It takes about 90-100 minutes by train to Fukuyama and about $60-70 \mathrm{~min}$ utes by car on the two-lane prefectural road. The population was 6,953 in 1990 , but is slightly decreasing. However, this decrease is not so serious as in the surrounding municipalities ${ }^{23}$. It was a coaching town in the Edo era and a county seat of Konu gun in the period 18901926. In 1956 when the author investigated the 
central place structure of Konu gun, stores not only of convenience goods but also of specialized goods like clothes (business suits), shoes and furniture were located along the shopping street (Morikawa, 1957). Most of the inhabitants within Konu gun visited Joge in order to buy specialized goods in those days, so that almost all areas of Konu gun belonged to its service area. In contrast, today almost all inhabitants of Konu gun including Joge itself visit Fuchu and Fukuyama by car for shopping purposes, except for purchasing convenience goods in Joge or in their own municipality. Clothing (business suits) stores disappeared and only two shoes stores remain in the shopping street. Because the revolutionary changes due to the location of large supermarkets have not occurred till today, Joge's townscape did not undergo dramatic change. However, the local railway, Fukuen line, constructed in 1938, no longer runs at a profit.

In Joge, administrative branches were not abolished and instead the establishment of a cattle health center is planned. Branch offices of banks (Hiroshima Bank and Ryobi-shinyo Bank) remain without any changes. There are no branch offices of large firms for managing the territory. Since there are four plants with more than 100 workers such as textile, electric and laundry service ${ }^{24}$, the day population is greater than the night population. Table 4 shows the changes in workers, commuters to other municipalities and commuters from the surrounding municipalities during the period 1965-1990. Although the population and workers of Joge have gradually decreased since 1950, commuters from the surrounding municipalities to Joge have increased.

The rate of students who wish to go to a university is not so high in Joge High School. Recently, most of the graduates tend to outmigrate to Hiroshima to enter a school of higher grade, including vocational schools as well as for seeking employment, though previously many graduates out-migrated to Tokyo and Osaka. It is because they can nowadays enjoy a better urban life in Hiroshima in addition to the convenience of life due to its vicinity to their home town, and they can easily return home in the future, if they live within the prefecture. But there are no graduates who desire to gain a job in Joge itself, because there are no entertain-

Table 4. Employed persons, commuters, and commuters to Joge

\begin{tabular}{|c|c|c|c|c|c|c|c|c|c|}
\hline & \multirow[b]{2}{*}{ Year } & \multicolumn{2}{|c|}{ Soryo } & \multicolumn{2}{|c|}{ Konu } & \multicolumn{2}{|c|}{ Jinseki } & \multicolumn{2}{|c|}{ Joge } \\
\hline & & number & $\begin{array}{r}1965 \\
=100\end{array}$ & number & $\begin{array}{r}1965 \\
=100\end{array}$ & number & $\begin{array}{r}1965 \\
=100\end{array}$ & number & $\begin{array}{r}1965 \\
=100\end{array}$ \\
\hline \multirow[t]{6}{*}{ Employed persons } & 1965 & 2,141 & 100 & 2,904 & 100 & 3,327 & 100 & 4,729 & 100 \\
\hline & 1970 & 1,914 & 89 & 2,756 & 95 & 3,089 & 93 & 4,687 & 99 \\
\hline & 1975 & 1,697 & 79 & 2.494 & 86 & 2,652 & 80 & 4,206 & 89 \\
\hline & 1980 & 1,491 & 70 & 2,399 & 83 & 2,508 & 75 & 4,086 & 86 \\
\hline & 1985 & 1,397 & 65 & 2,330 & 80 & 2,262 & 68 & 4,066 & 86 \\
\hline & 1990 & 1,146 & 54 & 2,174 & 75 & 2,057 & 62 & 3,736 & 79 \\
\hline \multirow[t]{6}{*}{ Commuters in total } & 1965 & 60 & 100 & 337 & 100 & 66 & 100 & 325 & 100 \\
\hline & 1970 & 193 & 321 & 398 & 118 & 131 & 198 & 378 & 116 \\
\hline & 1975 & 257 & 428 & 476 & 141 & 248 & 376 & 432 & 133 \\
\hline & 1980 & 362 & 603 & 547 & 162 & 305 & 462 & 485 & 149 \\
\hline & 1985 & 350 & 583 & 522 & 155 & 309 & 468 & 490 & 151 \\
\hline & 1990 & 345 & 575 & 553 & 164 & 330 & 500 & 477 & 147 \\
\hline \multirow[t]{6}{*}{ Commuters to Joge } & 1965 & 17 & 100 & 146 & 100 & 19 & 100 & $(4,772$ & 100) \\
\hline & 1970 & 87 & 512 & 195 & 134 & 49 & 258 & $(4,854$ & 102) \\
\hline & 1975 & 83 & 488 & 248 & 170 & 84 & 442 & $(4,497$ & 94) \\
\hline & 1980 & 86 & 506 & 286 & 196 & 101 & 532 & $(4,408$ & 92) \\
\hline & 1985 & 65 & 382 & 289 & 198 & 105 & 553 & $(4,496$ & 94) \\
\hline & 1990 & 64 & 376 & 292 & 200 & 109 & 574 & $(4,263$ & 89) \\
\hline
\end{tabular}


ment facilities for young people. In addition, there is a lack of pediatric and nose, ear and throat clinics.

Yoshida with a population of 11,527 is located about $44 \mathrm{~km}$ north of Hiroshima. It takes about 90 minutes on the two-lane Route 54 by bus and about $70-80$ minutes by car, owing to heavy congestion in the Hiroshima urban area. In Yoshida 443 or $6.9 \%$ of the workers commute to Hiroshima, especially to Asakita ward, and their number has remained unchanged.

Yoshida was also a coaching town similar to Joge in the Edo era and the county seat of Takata gun during the same period, but it has more favorable conditions than Joge. With the establishment of a large supermarket store by a Hiroshima company as the core store of a new shopping center constructed in 1992, Yoshida could expand its service area toward the northern direction. As a result, shopping visitors to Hiroshima have decreased. At the same time, the existing shopping street has markedly changed and only stores of traditional style remain there. A few large stores of foods and confectionery continue wholesaling activity on a small scale but are gradually declining.
Many administrative branch offices are concentrated here as well. A summary court and a welfare office of Yoshida were integrated to other towns, while Yoshida integrated an agricultural cooperative of the neighboring municipality, Mikaibara. There are no administrative branch offices with decreasing staff members. Since two industrial estates were constructed in 1974, various kinds of plants such as plastic, machine and food industries are located in addition to subcontracts of Mazda Automobile Ltd. Yoshida is estimated to be so comfortable for those living in Takata gun that there are many in-migrants from unfavorable areas within the same gun. Yoshida is not designated as a kaso (depopulated) area because of its slightly growing population. Even in such a situation, it seems that at least horizontal linkages with other small towns have not developed in Yoshida, though hierarchical linkages to Hiroshima may have become reinforced.

Table 5 corresponds to Table 4. Unlike Joge, however, the labor force in Yoshida is increasing so that the commuter area is expanding. Today, approximately $20 \%$ of the graduates of Yoshida High School remain in their home

Table 5. Employed persons, commuters, and commuters to Yoshida

\begin{tabular}{|c|c|c|c|c|c|c|c|c|c|c|c|}
\hline & \multirow[b]{2}{*}{ Year } & \multicolumn{2}{|c|}{ Yachiyo } & \multicolumn{2}{|c|}{ Midori } & \multicolumn{2}{|c|}{ Takamiya } & \multicolumn{2}{|c|}{ Koda } & \multicolumn{2}{|c|}{ Yoshida } \\
\hline & & number & $\begin{array}{r}1965 \\
=100\end{array}$ & number & $\begin{array}{r}1965 \\
=100\end{array}$ & number & $\begin{array}{r}1965 \\
=100\end{array}$ & number & $\begin{array}{r}1965 \\
=100\end{array}$ & number & $\begin{array}{r}1965 \\
=100\end{array}$ \\
\hline \multirow{6}{*}{$\begin{array}{c}\text { Employed } \\
\text { persons }\end{array}$} & 1965 & 2,343 & 100 & 3,218 & 100 & 4,262 & 100 & 4,038 & 100 & 6,267 & 100 \\
\hline & 1970 & 2,565 & 109 & 3,045 & 95 & 3,984 & 94 & 4,092 & 101 & 6,381 & 102 \\
\hline & 1975 & 2,251 & 96 & 2,672 & 83 & 3,540 & 83 & 3,854 & 95 & 6,322 & 101 \\
\hline & 1980 & 2,343 & 100 & 2,721 & 85 & 3,379 & 79 & 3,887 & 96 & 6,188 & 99 \\
\hline & 1985 & 2.401 & 103 & 2,523 & 78 & 3,259 & 77 & 3,724 & 92 & 6,322 & 101 \\
\hline & 1990 & 2,320 & 99 & 2,413 & 75 & 2,959 & 69 & 3,525 & 87 & 6,450 & 103 \\
\hline \multirow{6}{*}{$\begin{array}{l}\text { Commuters } \\
\text { in total }\end{array}$} & 1965 & 451 & 100 & 109 & 100 & 234 & 100 & 753 & 100 & 533 & 100 \\
\hline & 1970 & 560 & 124 & 298 & 273 & 403 & 172 & 925 & 123 & 748 & 140 \\
\hline & 1975 & 619 & 137 & 491 & 451 & 625 & 267 & 938 & 125 & 970 & 182 \\
\hline & 1980 & 757 & 168 & 705 & 647 & 783 & 335 & 1,129 & 150 & 1,047 & 196 \\
\hline & 1985 & 750 & 166 & 742 & 681 & 802 & 343 & 1,113 & 148 & 1,144 & 215 \\
\hline & 1990 & 815 & 181 & 803 & 737 & 766 & 327 & 1,133 & 150 & 1,382 & 259 \\
\hline \multirow{6}{*}{$\begin{array}{l}\text { Commuters } \\
\text { to Yoshida }\end{array}$} & 1965 & 72 & 100 & 52 & 100 & 18 & 100 & 83 & 100 & $(6,172$ & 100) \\
\hline & 1970 & 68 & 94 & 164 & 315 & 76 & 422 & 149 & 180 & $(6,373$ & 103) \\
\hline & 1975 & 87 & 121 & 252 & 485 & 128 & 711 & 183 & 220 & $(6,526$ & 106) \\
\hline & 1980 & 145 & 201 & 333 & 640 & 196 & 1,089 & 310 & 373 & $(6,970$ & 113) \\
\hline & 1985 & 163 & 226 & 367 & 706 & 195 & 1,083 & 340 & 410 & $(7,288$ & 118) \\
\hline & 1990 & 165 & 229 & 390 & 750 & 173 & 961 & 382 & 460 & $(7,323$ & 119) \\
\hline
\end{tabular}

Figures in ( ) show employed persons in Yoshida by place of work.

Sources: Population Censuses of Japan. 
town, though more graduates remained 20 years $\mathrm{ago}^{25)}$. In a manner similar to Joge, outmigrants to Tokyo and Osaka have decreased.

Joge and Yoshida are only two examples of small towns. Although both towns together have played an important role as service centers of low order, there are some differences between them, mainly based on their geographical location: Yoshida is now growing, while Joge is still declining and has no close linkage to Hiroshima or Fukuyama. It is noticeable, however, that both towns have their own commuting areas. If these small towns keep more jobs and are developed more vigorously as commuting centers for the neighboring rural areas, such a regional policy can possibly solve the depopulation problem and rectify regional disparities. According to Figure 8, municipalities with less than $20 \%$ of workers commuting to other municipalities are still prevalent.

Finally, we consider the reasons why small towns such as Joge and Yoshida are markedly different from those in Western countries. We cannot consider Japanese rural areas as "amenity-rich" rural regions in the Western European and North American sense ${ }^{26)}$. Almost all facilities of infrastructure are poorer and less favorable in rural areas than in urban areas. Notably, transportation conditions are tremendously inferior, as mentioned above in case studies of Joge and Yoshida, to the Western small towns, even if the rural inhabitants have more automobiles than urban ones. The level of education for children tends to be lower in rural areas as well. This is an important factor for evaluating the living conditions of a region, because Japan is a society in which socioeconomic status is largely determined by educational background. Additionally, in mountainous and island areas building lots are not sufficient. Even if there are no sharp contrasts between rural and urban areas as seen in developing countries, few inhabitants prefer to live in rural areas outside the suburban areas. It seems that many inhabitants even in suburban areas of large cities prefer to live in the cities, but must live in the suburbs in order to have their own homes.

\section{CONCLUSIONS}

In this paper we examined the changing features of a regional urban system under changing regional structure in the last few decades, taking Hiroshima prefecture as an example. We also noticed the present situation of small towns with two examples: Joge and Yoshida. The main results obtained are summarized as follows:

1) In the prefecture, only the Hiroshima metropolitan area has grown remarkably in the decade 1980-1990. Within the Hiroshima area, satellite towns such as Higashi-Hiroshima, Hatsukaichi etc. have grown specially rapidly and become centers of intermediate order, together with Asakita ward (formerly Kabe) located in the northern periphery of the densely inhabited area of Hiroshima. In contrast, the majority of municipalities in other areas are stagnant or decreasing in population and central function workers. This fact is remarkable in rural municipalities located far from Hiroshima or Fukuyama. Certainly, Fukuyama is growing but not so vital compared to Hiroshima. Therefore, we can assume that regional disparities between the Hiroshima metropolitan area-partially including the Fukuyama area-and other areas have expanded in the last few decades.

2) As Hiroshima has grown it has reinforced linkages with the main centers within the prefecture ${ }^{27)}$; in particular, the growing linkage between Hiroshima and Fukuyama is shown by increasing migration flows between 1967 and 1993. The rapid urban growth of Hiroshima in the narrow area of the prefecture seems to have made it difficult for small and medium-sized cities or small towns to develop horizontal linkages with each other.

3) Most of the small towns have been declining or stagnant till now. There are a few centers which have quite declined to the level of general rural municipalities. Joge has lost its service area of specialized goods while Yoshida has expanded its service area by establishing a new shopping center. Since no branch offices of large firms for managing a territory were established in Joge or in Yoshida, they could not strengthen linkages, at least from the viewpoint 
of service functions, with Hiroshima and Fukuyama as well as large metropolises. It means that they could not establish their new roles as the lowest unit of the Japanese urban system.

4) Nevertheless, Yoshida and Joge have small commuting areas. It is important for commuting centers to be formed in inland areas where workers cannot commute to large cities because of distance. If such commuting centers can become more vital and increase in number in inland and island areas through a program of social and economic promotion, it could play an important role for the improvement of living conditions in depopulated areas.

5) Despite an insufficient examination of the difference in vitality of small towns in Japan and Western countries, we can recognize different conditions of infrastructure, notably of transportation. In Japan there are large differences of living conditions between urban and rural areas ${ }^{28}$. Places of work are limited in rural areas, especially for highly qualified workers. There exist no "amenity-rich" rural regions as described in Hodge and Qadeer (1980). It is very difficult for small towns to maintain vital activities in the surrounding rural areas, in such conditions.

\section{Acknowledgments}

The author would like to express his sincere appreciation to officials of the Section of Statistics of Hiroshima Prefectural Government and also of Joge and Yoshida towns for their precious time and valuable information. The author wishes to thank a junior lecturer of our department Mr. T. Kawada for kindly offering his materials and our students Mr. K. Umeda and Mr. T. Hasegawa for their help in mapping. The author also would like to express his thanks to Mr. J. M. Chun, graduate student at University of California, for checking the English in this manuscript. This paper is part of the result of a project study supported by a Grant-in-aid from the Ministry of Education, Science and Culture (general study C, No. 06680143).

The author would like to dedicate this paper to the late em. Prof. Shun-ichi Kaneko at Oita University.

(Received Feb. 13, 1995)

(Accepted Mar. 30, 1995)

\section{Notes}

1) In the case of Hiroshima prefecture its prefectural boundary does not completely correspond to the unit of regional urban system because the eastern part of Yamaguchi prefecture belongs to the Hiroshima metropolitan area and the western municipalities in Okayama prefecture such as Kasaoka and Ibara cities connect closely to Fukuyama. In this paper, however, we regard the area of Hiroshima prefecture as a regional urban system.

2) However, this policy did not affect consumer behavior. Those villages with 1,500 to 5,000 people returned to net migration loss in the mid1980s (de Bakker, 1986).

3) Certainly, many of the Western countries which experienced counterurbanization in the 1970s were re-urbanized in the $1980 \mathrm{~s}$. But this phenomenon continued in the old Länder of Germany, France etc. in the 1980s. In Japan, it did not occur, although in-migrants to metropolitan areas decreased significantly in the second half of the 1970s (Morikawa, 1991).

4) This consists of the four old wards $(579,788$ pop.) and four new wards (505,917 pop.). The former, consisting of Naka, Nishi, Minami and Higashi wards, mostly correspond to the old urban area of Hiroshima city before the first amalgamation after World War II. The total population of Hiroshima was $1,085,705$ in 1990.

5) By analyzing the detailed data of the Retail and Wholesale Statistics (1956) and Establishment Statistics (1954), the author measured the centrality for each former small municipality by employing the direct count method of central functions (Morikawa, 1959). Therefore, it is difficult to compare central places between 1954/56 and 1990 in a strict sense. However, we can understand the changing features to some extent by comparing both centralities, based on the areal revision to present municipalities as shown in Table 1.

6) When for example a central place of the third order has a part of its central establishments we call a central place of 'incomplete 3 class'; 'complete 3 class' means to have almost all of the trait complex of establishments of the third class.

7) In those days Yuki in Jinseki gun had not sufficient establishments of central functions of each order, so that it was incomplete as a center of incomplete 4.

8) In the Report of Income Estimated on Municipality People in Hiroshima Prefecture in 1990, Hiroshima has the highest value of individual income per capita in the fiscal year 1987 within the prefecture and even the depopulated municipalities in the surrounding area of Hiroshima are relatively higher. In contrast, individual income in the southeastern part of the prefecture is at a relatively low level. In addition, the coefficients of variation decreased from 0.130 to 
0.100 in the period $1977-1987$, so that regional disparities seem to have fallen in Hiroshima prefecture. This fact is very curious, compared to the results of other materials which the author analyzed in this paper.

9) We define professional and technical workers, managers and officials, clerical and related workers as management function workers.

10) The average rates of Hiroshima prefecture and the whole country amount to $20.9 \%$ and $21.6 \%$, respectively.

11) As Meusburger (1993) pointed out, there is a remarkable gradient of entrance examination and social evaluation between Japanese universities. Nevertheless, the author thinks that university graduates are still significant as a criterion of measuring highly qualified workers.

12) The rates of migration flows between two municipalities are always counted by the population of the smaller one.

13) Comparing Figure 6 to the migration areas and population absorbing areas in 1969 (Morikawa, 1972), great changes can be recognized. Notably, the migration areas of Higashi-Hiroshima and Miyoshi emerged recently and the area of Kure expanded eastwards, while the areas of Onomichi and Fuchu were somewhat reduced.

14) Since the areas with two dimensions are pictured on one dimension, the sites of municipalities in Figure 7 are very skewed, especially for those far from Hiroshima.

15) In the growth rates of the migration flows between Hiroshima and other municipalities within the prefecture in the period 1970-1993, the hypothesis that the migration flows between Hiroshima and Fukuyama should indicate the highest growth rate, apart from the surrounding municipalities of Hiroshima, could not be confirmed. It seems that migration flows do not completely represent interurban linkages due to the influence of economic fluctuations.

16) Since Hiroshima is no normal prefectural capital but a regional metropolis, it is more difficult for other cities and towns to have horizontal linkages to each other.

17) Since these municipalities originally had few establishments till now, even a slight increase in the number of establishments causes high growth rate.

18) The linkages with headquarters outside the prefecture are omitted.

19) In Fukuyama, the department store Tenmaya and its subsidiaries called Tenmaya Sutoa, which are invested by a company in Okayama, have wide sales spaces. In addition, there are a number of branch stores of supermarkets invested from Hiroshima. The total sales space of the latter is larger than those of the former in total. At the same time, supermarket companies in Fukuyama and Kure have branch stores in their surrounding areas.

20) Although the author has not investigated in detail the regional administrative system in Western countries, there seems to be a remarkable difference from Japan. In Germany, for example, the most complex agglomeration of administrative functions is recognized in the level of county seats (Kreisstädte) and has been evidently developed since the early 20th century (Blotevogel and Schöller, 1988).

21) There are two types of locations in branch offices established by a prefectural government: concentration type and dispersion type (Morikawa, 1989). Since Hiroshima prefecture belongs to the latter and branch offices of various sections in the prefectural administration are not concentrated in one place but dispersed in some towns, such a phenomenon is more evident.

22) However, it does not seem to be necessary for urban grow th to establish branch offices of large firms, because even small towns that lack them are now growing in Western countries.

23) As mentioned in Yoshida, it rests on the existence of some in-migrants from the surrounding municipalities of Joge to Joge itself.

24) A laundry company with 750 workers in total has grown in Joge and its headquarters and main plant is located there. Since the branch plants are located in Hiroshima, Fukuyama, Fuchu, Yamaguchi, Iwakuni, Matsue, Gotsu, Niihama and Takamatsu, we must say that Joge has non-hierarchical linkage with them, at least concerning this function.

25) A teacher explained that many more parents have become financially able to provide higher education to their children compared to 20 years ago, because of the improvement of living conditions and the decrease in the number of children.

26) Indeed, because of the different size of settlements and other socioeconomic conditions it seems to be dissimilar to Western countries, as demonstrated in de Bakker (1986).

27) Although the author lacks data, the linkages with main cities of the neighboring prefectures are probably reinforced as well.

28) Based on the existence of various types of rural areas in Germany, they are called "gering verdichtete, agglomerationsferne Räume" in the new policy of regional planning (BfRBS, 1993, p. 7).

\section{References}

BfRBS: Bundesministerium für Raumordnung, Bauwesen und Städtebau (1993): Raumordnungspolitischer Orientierungsrahmen, 31S.

Blotevogel, H. H. und Schöller, P. (1988): Verwaltung und Zentralität. Akademie für Raumforschung und 
Landesplanung (hrsg.): Behördliche Raumorganisation seit 1980. Veröff. d. ARL, FuS., 171, 42-70.

Borcherdt, Ch. and Bauer, J. (1994): Besorgungsbeziehungen der Bevölkerung sowie Standorte von Ladengeschaften und Dienstleistungsbetrieben in den südlichen Ellwanger Bergen. Geographisches Institut der Universität Stuttgart, Materialien, 35, 38S.

Burns, E. K. and Trawis, R. W. (1982): Small town growth and metropolitan commuting: evidence from United States daily urban systems. Annals of Regional Science, 16, 75-78.

Dahms, F. A. (1988): Settlement dynamics, migration and commuting, Western Ontario, 1971-1985. Coppack, M., Russwurm, L. H. and Bryant, C. R. eds.: Essays on Canadian urban process and form III, The urban field. Dept. of Geography Publication Series 30, Univ. of Waterloo, 157-191.

de Bakker, D. (1986): Small service centres in the Dutch settlement system. Borchert, J. G., Bourne, L. S. and Sinclair, R. eds.: Urban systems in transition. Nederlandse Geografische Studies, 16, 85-96.

Gatzweiler, H. (1993): Metropolen oder Mittelstädte? Siedlungspolitik für Agglomerationsräume in den 90er Jahren. Raumforschung und Raumordnung, 51, 175-184.

Giese, E. (1991): Entwicklung der Einzelhandelszentralität zentraler Orte in Mittelhessen 1967-1986. Erdkunde, 45, 108-118.

Hart, J. F. (1988): Small towns and manufacturing. Geographical Review, 78, 265-287.

Hino, M. (1986): The location of branch offices of enterprises and the hierarchy of cities in Yamagata prefecture, Tohoku region, northeast Japan. Annals of the Japan Association of Economic Geographers, 32, 182-197. (JE)

Hodge, G. (1983): Canadian small town renaissance: implications for settlement systems concepts. $R e$ gional Studies, 17, 19-28.

Hodge, G. and Qadeer, M. A. (1980): The persistence of Canadian towns and villages: small is viable. Urban Geography, 1, 335-349.

Meusburger, P. (1993): The relationship between city size of the place of work and the qualification structure of jobs-a comparison between capitalist and socialist countries. Proceedings of the Nihon University International Symposium "Trends and prospects of world urbanization", Nov. 30-Dec. 2, 1992. University Research Center, Nihon University, Tokyo, 147-177.

Morikawa, H. (1957): Fukuyama chiho no chushinchi kozo (The structure of central places in the Fukuyama region). Graduation Thesis (Department of Geography, Univ. of Hiroshima) Unpublished. (J)
Morikawa, H. (1959): Verteilung der zentralen Siedlungen und ihre Entwicklung in der Regierungsbezirke Hiroshima. Geographical Review of Japan, 32, 595-613. (JG)

Morikawa, H. (1972): The movement of population in Hiroshima prefecture. Committee for Commemoration Volume for Professor K. Funakoshi, University of Hiroshima ed.: Chirikagaku no shomondai (Essays of geographical sciences). Committee for Commemoration Volume for Professor K. Funakoshi, University of Hiroshima, 10-15. (J)

Morikawa, H. (1985): The Japanese urban system based on the analysis of internal migration. The Human Geography, 37, 20-38. (JE)

Morikawa, H. (1989): Intermediate administrative areas and planning regions within a Japanese prefecture. Annals of the Japan Association of Economic Geographers, 35, 295-311. (JE)

Morikawa, H. (1990): Regional urban systems in Japan. The Human Geography, 42, 97-117. (JE)

Morikawa, H. (1991): The present aspect of urbanization and structural change of urban systems in Japan. Geographical Review of Japan, 64A, 525-548. (JE)

Morikawa, H. (1994): Regional structures of economic linkages between Japanese cities based on the analysis of bank branch networks. The Human Geography, 46, 166-186. (JE)

Pompili, T. (1992): The role of human capital in urban system structure and development: the case of Italy. Urban Studies, 29, 905-934.

Pred, A. R. (1971): Large-city interdependence and the preelectronic diffusion of innovations in the U.S. Geographical Analysis, 3, 165-181.

Pumain, D. and Saint-Julien, Th. (1984): Evolving structure of the French urban system. Urban Geography, 5, 308-325.

Shepherd, J. and Congdon, P. (1990): Small town England: population change among small to medium sized urban areas, 1971-81. Progress in Planning, 33, Part $1,111 \mathrm{p}$.

Simmons, J. W. (1986): The impact of distribution activities on the Canadian urban system. Borchert, J. G., Bourne, L. S. and Sinclair, R. eds.: Urban systems in transition. Nederlandse Geogr. Studies, 16, 60-69.

Tsuneda, M. (1993): Chugoku chiho niokeru iyakuhin hanbaimo no kukanteki tenkai (The spatial pattern of marketing network organized by the medical manufactures in Chugoku region). Graduation Thesis (Department of Geography, Univ. of Hiroshima) Unpublished. (JE) 


\title{
広島県における地域的都市システムの变化
}

\author{
森 川 洋*
}

本稿では, 広島県を事例として, 最近 20〜30 年間に おける地域的都市システムの構造変化を考察した。その 際にはとくに，中小都市間の水平的結合の存在ととも に, 低次中心地の機能変化に注目した。その結果, 過去 $20 \sim 30$ 年間に広島大都市圈が著しく成長し, 他地域と の地域間格差が拡大してきたことが判明した。しかも広 島は, 高次中心地, 特に福山との機能的結合を強化して きた。しかしながら，広島の急激な成長と狭小な県域の ため, 県内中小都市相互の水平的結合はそれほど発達し
なかった。欧米諸国では低次中心地は農村地域の豊かな アメニティのもとで成長しているといわれるが，広島県 では低次中心地の大部分は不利な生活条件のもとで，今 日まで衰退またはせいぜい停滞してきた。しかし，低次 中心地のなかにも，吉田や上下などのように，小規模な がらも自己の通勤圈をむつものがあり，これらの中心地 が成長することは過疎地域の生活条件の改善に大きく貢 献するものと考えられる。 